\title{
Investigating the Simultaneous Ecological Operation of Dam Gates to Meet the Water Flow Requirements of Fish Spawning Migration
}

\author{
Wenhai Zhang', ${ }^{1,}$ Hu Peng'*, Yangwen Jia ${ }^{2}$, Guangheng Ni , \\ Zefan Yang ${ }^{2}$, Qinghui Zeng ${ }^{2}$ \\ ${ }^{1}$ Tsinghua University, Hai Dian, Beijing, China \\ ${ }^{2}$ China Institute of Water Resources and Hydropower Research, Beijing, China
}

Received: 26 November 2017

Accepted: 16 April 2018

\begin{abstract}
The construction of gates in watercourses could change the original hydrological and hydrodynamic processes of drainage basins, eventually having a widespread cumulative influence on river habitat and fish resources. In this study, the hydrodynamic force in the Yongjiang River basin, China, was calculated using the MIKE FLOOD model, including water depth and flow velocity. Subsequently, the habitat conditions suitable for yellowcheek carp were used to analyse ecologically suitable flow for this target species during the spawning period at the main spawning site (Fenghua River). Different schemes of simultaneous operation of the dam gates on the Fenghua and Yaojiang rivers were simulated after gate construction on the Yongjiang River estuary, and their influence on fish spawning and migration in the main stream was investigated. During the fish spawning period, the ecological flow for facilitating yellowcheek carp spawning in the Fenghua River was $160 \mathrm{~m}^{3} / \mathrm{s}$. The discharged water flow of gates increased to 90 and $250 \mathrm{~m}^{3} / \mathrm{s}$, respectively, in the tributaries of the Yaojiang and Yongjiang rivers, causing the average flow velocity of the target watercourse to increase by $0.2 \mathrm{~m} / \mathrm{s}$. Based on our results, we provide recommendations for regulating water flow to enhance ecological watershed planning after gate construction along watercourses.
\end{abstract}

Keywords: Yongjiang River, gate operation, fish habitats, ecological water requirement

\section{Introduction}

Recent global climate changes have altered the land utilisation type of flood pains; furthermore, the influence of human activities on water discharge regulation has caused extensive changes to the hydrological characteristics of watercourses. Moreover, the original mobility, connectivity, and hydrodynamic characteristics of watersheds have further changed along with the development of freshwater resources and the construction of dam gates. With the acceleration of dam gate construction in watersheds, natural river-type water bodies turn into lake-type water bodies upstream of gates, and the hydrodynamic gentleness of watersheds caused by the simultaneous operation of dam gates has 
a widespread influence on the ecological environment, such as the loss of fish spawning stimulus signals [1], reduction of fish habitats [2], and loss of fish diversity [3].

At present, the scientific community and administrative departments are mainly focusing on how controlling water discharge via hydraulic engineering influences the ecological environment. The present hydraulic structure has several economic benefits, but inevitably changes the natural hydrological regime of rivers [4]. Fish habitat fragmentation is more influenced by the construction of dam gates in main streams than in tributaries [5]. The construction of gates at hydraulic plants causes changes to the hydrological processes such as flow quantity, frequency, duration, flow velocity, and water depth. These changes mainly lead to gradual degradation of the structural functions of fish stocks [6]. After dam gate construction, the cycle of the natural flood pulse becomes artificially averaged because of reservoir flood regulation, which has a major influence on the spawning and growth processes of aquatic organisms [7-9]. Flow velocity plays a crucial role because it determines the amount of nutrients retained and the quantity of oxygen delivered during fish spawning [10]. The weakening of the water flow stimulus causes fish gonad development to decline, with the reduction of spawning quantity in watersheds potentially having a long-term cumulative influence on the population structure of fish stocks. Therefore, a certain amount of basic flow and peak flows should be maintained in watersheds. The hydraulic conditions in fish life histories, such as water depth and flow velocity, should be adequately maintained by regulating dam gates as an effective cost-saving measure to recover fish habitats [11, 12].

Regarding the ecological effects of dam gate operation control of watersheds, in recent years, researchers have gradually shifted their focus from water yield requirements of macroscopic watershed ecological systems to water yield regulation during the crucial period of organisms present in the watersheds. A clearer fish-hydrologic response relationship has been established. Richter [13] generated 33 indexes to evaluate the extent of changes in ecological systems for rivers and relatively comprehensively established the relationship between hydrology and ecology. However, this relationship is based on the evaluation criteria of regional investigations, limiting its potential wider use. Moreover, the relationship between fish and hydrologic ecology in these indexes is represented by the occurrence time of annual extreme flow, without a specific physical mechanism to quantify the specific relationship between fish spawning and physical variables changes in hydrodynamic conditions. The theoretical system of Instream Flow Incremental Methodology (IFIM), which was developed by Bovee [14], is a widely used method for evaluating the status of rivers. In this system, the biological and hydrological response relationship is quantified by establishing the relationship between hydrological factors and conditions favourable for fish habitats. Based on the IFIM theory system, researchers developed the traditional physical habitat simulation model (PHABSIM) to determine the biological and hydrological response relationship of fishes in more detail, and to establish habitat suitability indices by quantifying the application scopes of various factors such as flow velocity, water depth, and substrate for target species. Further, PHABSIM assumes that the weighted usable area (WUA) reflects the available quantity of fish habitats under upstream inflow conditions $[15,16]$. Yao [17] developed a twodimensional habitat evaluation model and established the ecological response relationship of specific fish species with watershed hydrology based on the IFIM theory. The author also revealed the influence of the Colorado (USA) high-flow environment on the habitat quality of rainbow trout by analysing the habitat quality in a high-flow environment before and after the evolution of sediment erosion and deposition. In terms of the current habitat flow evaluation, several studies have investigated the biological responses according to the quantity of effective habitats; however, the biological plaque characteristics have not been considered. Therefore, based on the quantity of effective habitats, Chen [18] optimised the original PHABSIM habitat model by adding the evaluation of habitat plaque quality (namely, the habitat fragment index [HFI]), and suggested a reasonable flow plan to protect the spawning of Spinibarbus hollandi fish. Based on the evaluation of ecological flow by using a number of habitats, Li [19] evaluated the quality of fish habitats by introducing fragmentation factors and connectivity indices of the two sexes derived from landscape ecology. Previous studies based on the IFIM theory only evaluated the water requirements of fish stocks within the microscopic spawning site, overlooking the hydrodynamic requirements of fish spawning and migration [20]. Therefore, these studies were relatively limited in evaluating the water requirement conditions of fish habitats. Furthermore, very few studies have focused on the hydrodynamic conditions required for fish spawning and reproduction. In fact, the hydrodynamic conditions of spawning and migration directly influence fish gonad development and changes in roe quantity. Furthermore, suitable flow at the spawning site determines the odds of scrod survival; hence, it is essential to conduct water requirement evaluation to determine the efficiency and applicability of an ecological operation during spawning and reproduction.

In this study, the flow requirements at a fish spawning site were evaluated and the flow stimulus required for fish migration was quantitatively evaluated. The Yongjiang Watershed (China) was selected as the research area, and historical observational data were used. The hydrodynamic model and requirements of yellowcheek carp habitat indices were combined to evaluate the suitability of fish habitats under different incoming flows. Further, the flow field results during the 
simultaneous regulation of different flows between the Fenghua and Yaojiang rivers were obtained after gate construction on the Yongjiang River by using the MIKE FLOOD model. This study aimed to: 1) determine the suitable flow velocity at the Fenghua River spawning site in order to meet the requirements of the largest suitable habitat area for yellowcheek carp and 2) generate an optimal scheme for the hydrodynamic regulation of flow velocity to ensure the stimulation of migration in fish. We expected our results to provide sufficient information to propose a simultaneous operational scheme of dam gates to meet the hydrodynamic requirements during fish spawning migration and roe incubation.

\section{Materials and Methods}

\section{Research Area}

The main stream of the Yongjiang River is formed by two tributaries, the Fenghua and Yaojiang rivers, joining at the estuary of three rivers. The Yongjiang Watershed is located in the eastern coast of Zhejiang Province and finally flows into the East China Sea at Zhenhai estuary at Ningbo City (Fig. 1). The Yongjiang watershed covers a total area of $5683.6 \mathrm{~km}^{2}$. In the south, it starts from the Fenghua River and originates from Xiujian Mountain on the eastern side of Siming Mountain; the river system is $93.4 \mathrm{~km}$ long. In the north, it starts from the Yaojiang River and originates from Xiajialing Village on the northern side of Siming Mountain; the river system is $107.4 \mathrm{~km}$ long. The main stream of Yongjiang, which is joined by two rivers, is $25.6 \mathrm{~km}$. The average gradient of the watercourse (mainly the Fenghua River) is $8.3 \%$, and the riverbed substrate mainly consists of clayey silt with the median size of substrate ranging from 0.008 to $0.052 \mathrm{~m}$. The watershed discharge mainly originates from rainfall, and seasonal changes are obvious. The discharge volume of the flood season accounts for $69 \%$ of that in the entire year [21]. Three large-scale reservoirs are present in the Fenghua River (the total storage of Jiaokou, Tingxia, and Hengshan reservoirs is $119.81,150.24$, and 111.8 million $\mathrm{m}^{3}$, respectively). The annual average discharge volume is $60 \mathrm{~m}^{3} / \mathrm{s}$. Yaojiang dam was constructed and began to be operated from 1959; before that, the tributary Yaojiang tributary flowed into the estuary of the three rivers. The drainage period is mainly the flood season, and the annual average discharge volume is $40 \mathrm{~m}^{3} / \mathrm{s}$ [22].

In recent years, because of the deterioration of water environment quality and fish habitat conditions in the estuary of Yongjiang and offshore areas, it has become difficult to detect many valuable and rare sea migratory fish such as Reeve's shad, Indian knife fish, and eels [23]. Even freshwater fish are severely threatened because of the water environmental deterioration. Considering the target requirements of Ningbo City with regard to the comprehensive perspective of the economy, and flood prevention or control, landscape, and ecology, the Ningbo Government plans to build gates on the estuary of the Yongjiang River. After gate construction, the watercourse at the gate will not be tidal, and natural water level fluctuations will be remarkably reduced, which could have an important influence on the rhythm of fish spawning migration. Furthermore, the water ecosystem structure and functions of the Yongjiang River could be altered. Given that marine fish have stopped migrating in the watershed (and maybe gone extinct), gate construction on the estuary might further obstruct fish migration pathways. Thus, a new freshwater ecological environment needs to be developed at the gate of the Yongjiang estuary. Freshwater migratory fish were selected as target species for water ecological protection in the Yongjiang River. These species were used to explore the hydrodynamic conditions required during their crucial life stages, and conduct the simultaneous ecological operation of the dam gates. This process is essential to alleviate the ecological influences of gate construction in Yongjiang estuary, and to reconstruct a healthy water ecosystem in the watershed.

\section{Target Species and Suitable Flow Conditions}

About 100 types of freshwater fish live in the Yongjiang Watershed [24]. Given the habits, feeding habits, and abundance of spawning fish, we selected yellowcheek carps as the representative species of the Yongjiang water ecosystem. This species is categorised as a sarcophagous fish, and shows semi-migration activity up the river. The species is at the top of the food chain for aquatic organisms, playing an important role in controlling the structure of the fish community and maintaining a balanced water ecosystem [25]. Further, yellowcheek carps produce drifting roe, making them highly sensitive to hydrodynamic characteristics, such as flow velocity and water level, unlike other species. Therefore, this species should be given priority during the ecological regulation of the watershed.

Yellowcheek carps spawn and reproduce from April to August every year. The scrod usually prefer to move in the upper water area (approximately 1.2-2 m) of the river. The suitable $\mathrm{pH}$ is around $6.5-8.5$, and the most suitable spawning temperature is $20-27^{\circ} \mathrm{C}$. The dissolved oxygen content for regular growth and development is $4 \mathrm{mg} / \mathrm{L}$ or higher. Water flow stimulation is especially important during the spawning period of yellowcheek carp, and suitable water flow velocity ranges from 0.2 to $0.6 \mathrm{~m} / \mathrm{s}$ [26]. During the early (II-III) and midterm gonad development stages of yellowcheek carp, nutrition - not water flow - is an important condition; however, in the late stage (IV to V), water flow stimulus is needed [27]. Previous studies on yellowcheek carp revealed that the fish colony swims toward the upper and middle reaches of rivers and seas under natural conditions [28-30]. When the flow velocity increases by $0.20 \mathrm{~m} / \mathrm{s} /$ day and lasts for $1-3$ days, the conditions for stimulating parent fish spawning are met [31]. 
After spawning, low-flow velocity for the safe drifting of roe is $0.20 \mathrm{~m} / \mathrm{s}[32,33]$. Analyses of the reproductive habits of yellowcheek carp and on-site interviews and investigations suggest that their main spawning sites extend from Yinzhou Bridge across the Fenghua River to the Chenglang Weir, which are characterised by winding and ponding-vortex flow (i.e., the golden stream segment in Fig. 1), while the downstream segment and Yongjiang gate segment are the pathways for yellowcheek carp spawning and migration.

\section{Data Sources}

The simulated hydrodynamic topographic data of the watercourse were selected from watercourse mapping (measuring scale: 1:2000) developed by Zhejiang Design Institute of Water Conservancy and Hydro-Electric Power in June 2015. The hydrological data were selected from the data measured by the Survey Bureau of Hydrology and Water Resources along the downstream regions of the Fenghua River in the flood season in 2015. Furthermore, the hydrological data of the neap season from 2016 June 17 to 18 were selected as model calibration data, and the measured hydrological data of the spring tide season from 2016 June 24 to 25 were considered as the verification data. In addition, four fracture surfaces, including the Chen Lang Weir (CS6), the estuary of three rivers (CS2), Yang Mu Qi (CS3), and Zhen Hai (CS4), were selected as the verified fracture surfaces of the hydrodynamic model (Fig. 1).
Model Introduction

\section{PHABSIM}

In PHABSIM, the suitability curves of the habitat environment (water depth, flow, substrate, and temperature) of a target species during their crucial life stages are first constructed, followed by calculations of the hydrodynamic and aquatic environmental factors corresponding to different levels of flow. Habitat suitability indices are then obtained from the suitability curves. The multiplication of these suitability indices with the watershed area of the habitat yields the weighted usable area (WUA) under the given hydrodynamic conditions. Through determining the relationship between the number of weighted habitat areas and flow, we are then able to assess the suitability of the flow adjustment that was made for the protection of the target species [34]. Unlike other ecological water requirement methods, such as the hydrologic and hydraulic methods, the PHABSIM method quantitatively assesses the impact of changes to water flow on the surrounding habitats based on the requirements of aquatic organisms in the physical environment. Therefore, this model has strong physical significance [35] and has been widely used by scholars [36].

The main computation process of PHABSIM is divided into two parts [37]: hydraulic and habitat modules. The hydraulic module mainly includes a logarithmic regression method (IFG4), channel transportation method (MANSQ), and standard step

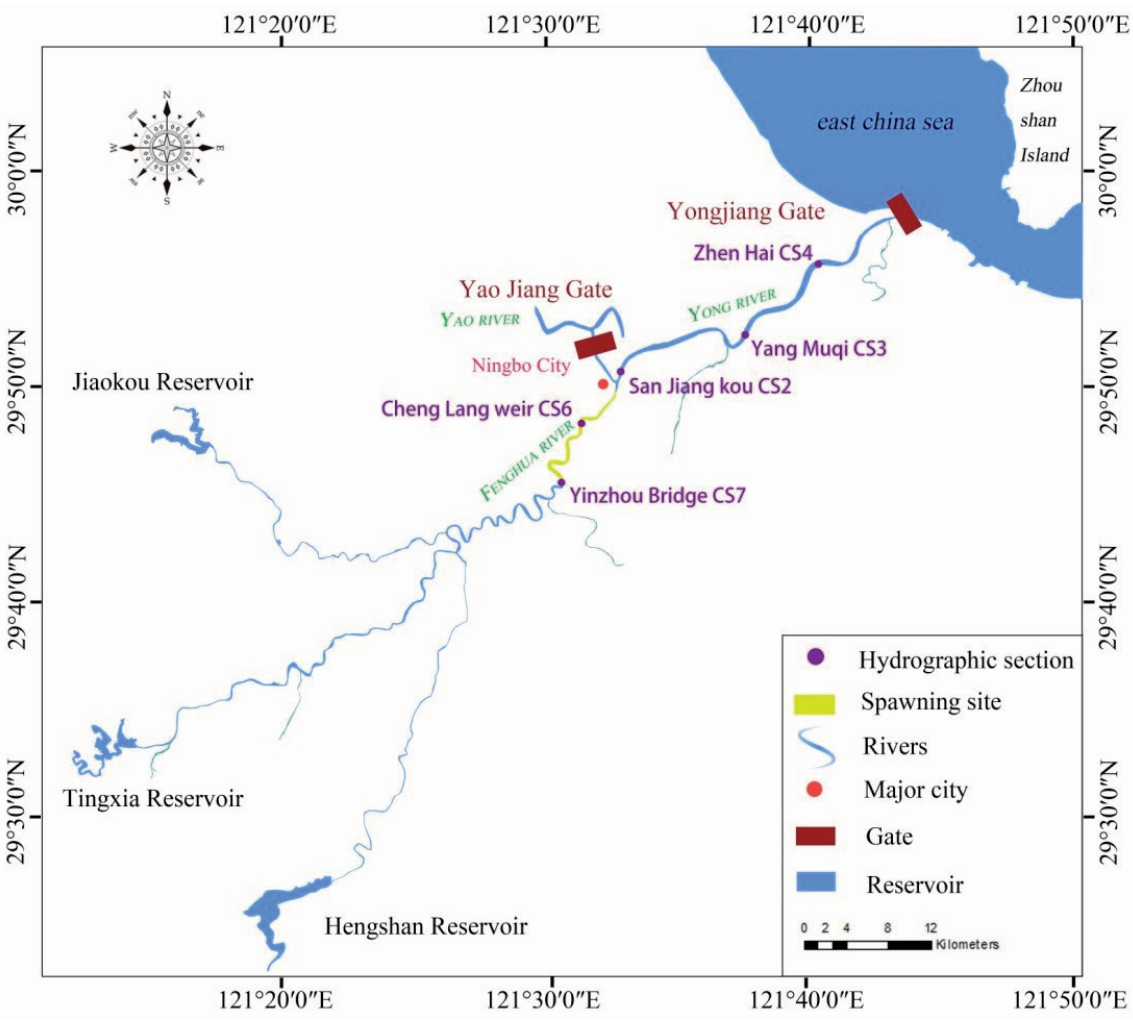

Fig. 1. Research area overview. 
method (WSP). The habitat module is mainly computed using the HABITAT method [38].

Based on the hydrodynamic module, the model first calculates the flow velocity and water depth distribution of the investigated river reach under different flow conditions, and then obtains the habitat suitability indices corresponding to the flow velocity and water depth for single computing units based on the habitat suitability curve of target species. Finally, it calculates the WUA of the habitat for the entire river reach [39]. The computational formula is as follows:

$$
W U A=\sum_{\mathrm{i}} F\left[f\left(V_{i}\right), f\left(D_{i}\right)\right] * A_{i}
$$

...where $F[]$ is the combined suitability factor (CSF) in the $\mathrm{i}^{\text {th }}$ node area; $\mathrm{A}_{\mathrm{i}}$ is the water area of the $\mathrm{i}^{\text {th }}$ computing element; and $f\left(V_{i}\right), \quad f\left(D_{i}\right)$ are single-factor suitability indexes of flow velocity and water depth in the $i^{\text {th }}$ computing element, respectively, which are obtained from the suitability curves corresponding to flow velocity and water depth.

The CSF is an important parameter for habitat simulation. Considering that two parameters $f(V), f(D)$ have the same influence as suitability indexes, this study selected the geometric method to obtain the CSF value as follows:

$$
C S F=\sqrt[3]{f(V) * f(D)}
$$

...where the range of CSF is $0 \sim 1$, which is defined as $0 \sim 0.2$ for low suitability, $0.2 \sim 0.6$ for moderate suitability, and $0.6 \sim 1$ for high suitability.

\section{MIKE FLOOD Module}

The MIKE FLOOD module is a set module of the MIKE-series numerical model developed by the Danish Hydraulic Institute (Dairy Herd Improvement), and has been widely used to simulate hydrodynamic factors at various sites, including rivers, lakes, estuaries, bays, coasts, and ocean currents, as well as at complex hydraulic structures such as gates, culverts, bridges, and weirs [40].

The MIKE 21 FM module describes the watercourse topography in the form of unstructured grids and adopts the alternation direction implicit (ADI) line method for the space-time integral of quality and momentum equations. In this module, the vertical average flow factor was selected as the research object to realise the simulated computation of flow velocity and water level in a two-dimensional flow field [41]. According to the requirements of the hydrodynamic simulation process, the MIKE 11 module presupposes the operation rule to control the water yield of rivers. All control strategies were organised using 'if' statements. That is, each statement is used to define the discriminating conditions of arbitrary quantities. Only if all judgment conditions are evaluated as true in the statement can the strategy be implemented to realise the gate functions. The MIKE FLOOD module first obtains dynamic coupling computations for the flow field of MIKE 21 FM (the two-dimensional hydrodynamic module) as well as the gate functions of MIKE 11 (the single-dimensional hydrodynamic module), and then obtains the information of each grid cell node in the two-dimensional watercourse controlled by gates.

\section{Analytical Methods}

In this study, the optimum scheme of dam gate operation that can meet the water flow requirements during the entire process of fish spawning migration was determined using two aspects. First, the suitable ecological flow of the spawning site was calculated. Based on the findings of existing studies on the required suitable hydrodynamic conditions of yellowcheek carp spawning, we established the suitability curve of flow velocity and water depth, and then generated the relationship curve of WUA and flow volumes by using PHABSIM to determine the minimum upstream flow to meet the water flow requirements at the fish spawning site. Second, the optimum discharge volume from dam gates was analysed for the stimulation of fish migration. To maintain suitable flow to the fish spawning site, different discharge flow schemes were set at the gates in the Yaojiang and Yongjiang Rivers to evaluate the effects of different flow velocities in the research area under different schemes (Table 1). Furthermore, the suitable flow velocity range of fishes was considered to determine the optimum dam gate operation scheme.

Table 1. Ecological flow operational scheme of migratory stimulation signals.

\begin{tabular}{|c|c|c|c|}
\hline Scheme & $\begin{array}{c}\text { Fenghua River Incoming Flow } \\
\left(\mathrm{m}^{3} / \mathrm{s}\right)\end{array}$ & $\begin{array}{c}\text { Yaojiang River Discharged Flow } \\
\left(\mathrm{m}^{3} / \mathrm{s}\right)\end{array}$ & $\begin{array}{c}\text { Discharged Flow of Yongjiang Gate } \\
\left(\mathrm{m}^{3} / \mathrm{s}\right)\end{array}$ \\
\hline 0 & 60 & 40 & 100 \\
\hline 1 & 160 & 40 & 200 \\
\hline 2 & 160 & 60 & 220 \\
\hline 3 & 160 & 80 & 240 \\
\hline 4 & 160 & 90 & 250 \\
\hline 5 & 160 & 100 & 260 \\
\hline
\end{tabular}



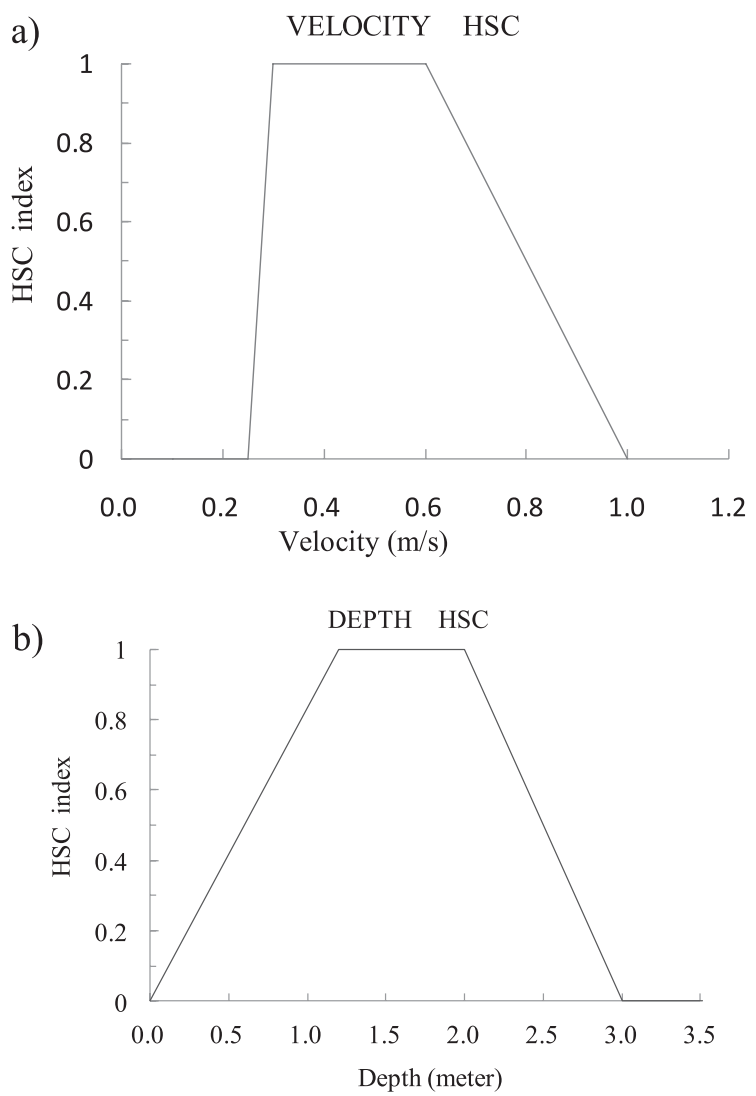

Fig. 2. Flow velocity and water depth suitability curves of pelagic roe during the spawning period: a) flow velocity suitability curve, b) water depth suitability curve.

\section{Method of Computing Suitable Ecological Flow at the Spawning Site}

The hydraulic habitat conditions of yellowcheek carp are as follows: optimum water depth 1.2-2 m and optimum flow velocity $0.2-0.7 \mathrm{~m} / \mathrm{s}$. According to these requirements, the suitability curve of important hydraulic factors was determined, such as water depth, flow velocity, and substrate (Fig. 2). Because of the construction of an artificial channel, the substrate at the research area would basically remain consistent and was considered as one.

The hydraulic module was used to calculate the hydraulic factors of each cell node in the flow field for different flows. The one-dimensional hydrodynamic model did not consider the influence of interval catchments; therefore, its simulation range scale was limited. MIKE FLOOD software was used for the hydraulic simulation. By using the complete riverbed topographical data, we applied the finite volume method for the spatial dispersion of the computational domain to calculate the two-dimensional flow field and water depth distribution of the cell nodes on the habitat planes as well as to evaluate the influence of local flow structure on habitats in detail.

The habitat suitability curve was used to determine the habitat suitability indices corresponding to the hydraulic factor and to obtain the weighted summation of the combined suitability indices and the effective areas of different cells. By analysing the fitted curve relationship of the effective habitat area under different flows during the spawning period, we estimated the flow that corresponded to the point where the slope of the fitted curve decreased obviously along with the upstream incoming flow requirements and guaranteed suitable flow conditions at the fish spawning site.

\section{Analysis of the Minimum Dam Gate Discharged Flow for Stimulating Fish Migration}

Scheme setting: Table 1 shows the united operational schemes of different flows from the Fenghua River, discharged flow at Yaojiang gate, and discharged flow downstream of Yongjiang gate. Scheme 0 shows the average annual flow of the Fenghua, Yaojiang, and Yongjiang rivers before the construction of Yongjiang gate. In Scheme 1, the suitable ecological flow at the spawning site was determined by computing the suitable ecological flow at the spawning site, and was used as the flow of the Fenghua River. The average annual flow of the Yaojiang River was used for Yaojiang gate. Moreover, the water balance computation was used to obtain the discharged flow of Yongjiang gate. The study used $0.2 \mathrm{~m} / \mathrm{s}$ as the minimum flow velocity change rate to stimulate fish spawning migration and compared the difference between the flow velocity distribution of Scheme 1 and that of Scheme 0. We aimed to verify whether the suitable ecological flow at the spawning site, determined by computing the suitable ecological flow at the spawning site, could meet the requirements of flow velocity changes to stimulate fish spawning. If the difference value of Scheme 1 could reach the flow velocity change rate to stimulate fish spawning in the Fenghua River spawning site, the suitable ecological flow at the spawning site could be determined as the incoming flow volume of the Fenghua River via ecological regulation. The flow velocity change rate in the Fenghua River spawning site had to reach the minimum flow velocity to stimulate fish spawning and migration. When the upstream water quantity remained the same, the Yongjiang River, located downstream of San Jiangkou, caused the downstream flow velocity to decrease because of the widening of the watercourse; hence, scheme 2-5 gradually increased the discharged flow volume at the Yaojiang gate while maintaining the suitable flow at the fish spawning site. Moreover, the corresponding discharged flow volume from Yongjiang gate was obtained using the water balance computation.

The principles of optimal scheme selection: according to the simulated results of the MIKE FLOOD model, the differences in flow velocity before and after the simultaneous regulation of discharged flow volumes at different gates were compared (Table 1), and the degree of the minimum flow velocity change rate to stimulate fish spawning and migration was analysed for 
every scheme. Finally, the selected scheme was required to meet the objectives of the minimum flow velocity change rate and to ensure that the flow velocity would not exceed the flow velocity range suitable for the fish.

\section{Results and Discussion}

\section{Hydrodynamic Model Verification}

The measured and simulated values of tidal-level time series on every fracture surface are shown in Fig. 3. The correlation coefficients $\left(\mathrm{R}^{2}\right)$ of simulated and measured values were more than 0.95 on each fracture surface, which was consistent with the simulation precision requirements. In the peak and valley intervals of the tidal level, the error was relatively larger, where the maximum tidal range occurred at about 20:00. The difference between the simulated tidal on the fracture surface of the Chen Lang Weir and the estuary of three rivers and the verified tidal was $0.32 \mathrm{~h}$, which was expected, and the maximum error of the corresponding tidal level was $0.029 \mathrm{~m}$.

The measured and simulated values of the average flow velocity that changed with time on each fracture surface are shown in Fig. 4. The $\mathrm{R}^{2}$ of the simulated and measured values for the average flow velocity were more than 0.75 on each fracture surface, which was consistent with the simulation precision requirements.
The maximum tidal range was $0.36 \mathrm{~h}$, and the maximum error of the average flow velocity was $0.19 \mathrm{~m} / \mathrm{s}$ on the fracture surface of Yang Mu Qi at 06:00. The error of other fracture surfaces mainly existed at the peak and valley time of the fluctuated flow velocity.

Verification of the maximum flow direction of each section is shown in Table 2, in which the maximum flow error is within $20^{\circ}$, in line with the simulation accuracy requirements. In the comparison of measured and simulated values, the maximum flow direction when the tide of the simulated value and the measured value differed by $18^{\circ}$, while the maximum flow ebb of the simulated value and the measured value differed by $17^{\circ}$. Both the maximum error of the tide and the ebb occur in the CS4 section.

Flow volume, tidal level, flow velocity, and flow direction suggested that the maximum error was within a reasonable range. Thus the established model adequately described the hydrodynamic process of the research area and satisfied the application conditions.

\section{Suitability of Ecological Flow at the Spawning Site during the Fish Spawning Period}

The MIKE and PHABSIM models were coupled to evaluate the suitable ecological flow at the yellowcheek carp spawning site of the Fenghua River. The flow of the Fenghua gradually increased from 20 to $200 \mathrm{~m}^{3} / \mathrm{s}$, and the corresponding WUA of yellowcheek carp continued a)

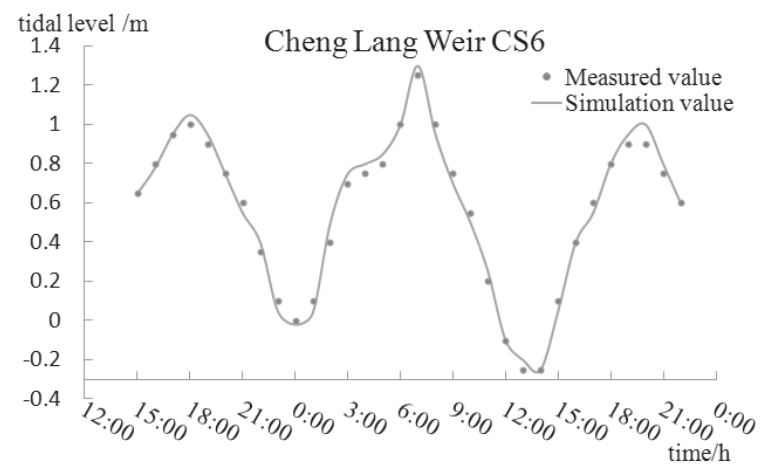

b)

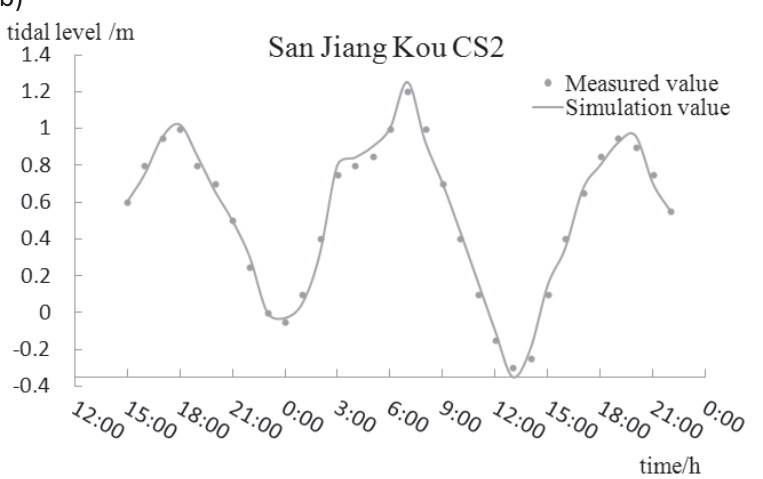

c)

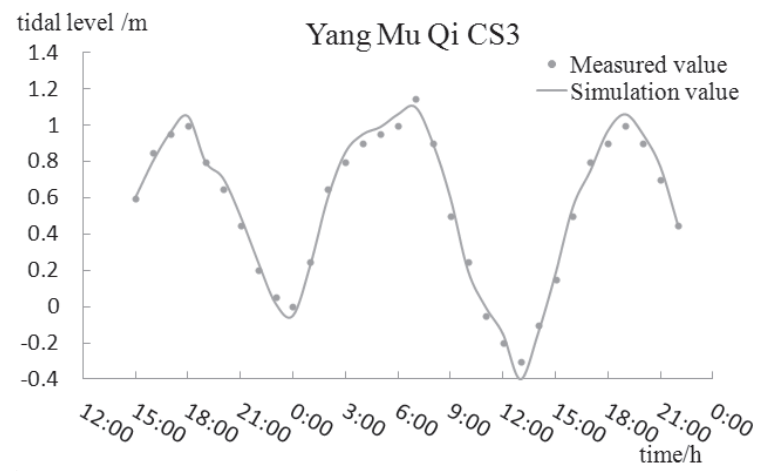

d)

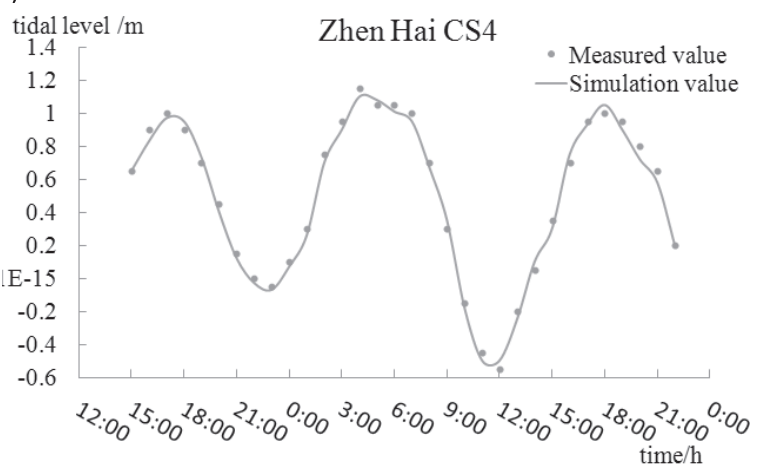

Fig. 3. Comparison of the measured and simulated values of the tidal level time series on each fracture surface: a) Tidal level of the CS6 Chen Lang Weir fracture surface; b) Tidal level of the CS2 San Jiang Kou fracture surface; c) Tidal level of the CS3 Yang Mu Qi fracture surface; and d) Tidal level of the CS4 Zhen Hai fracture surface. 
a)

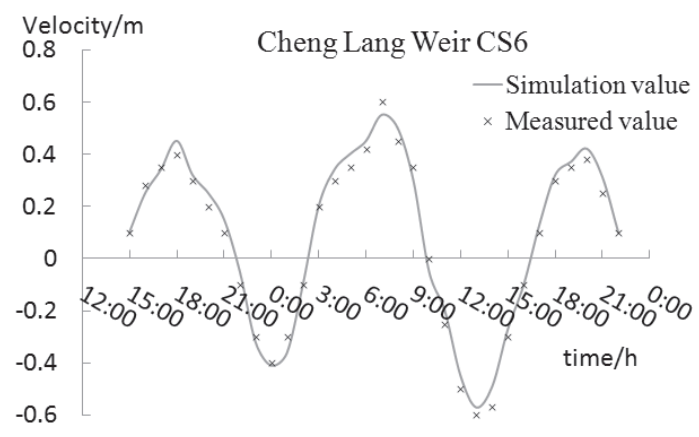

b)

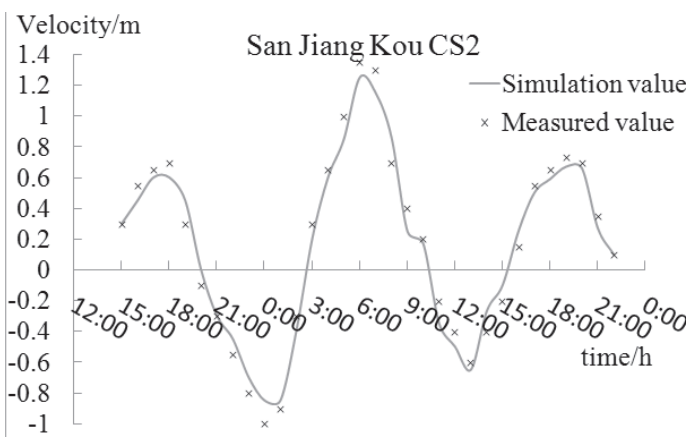

c)

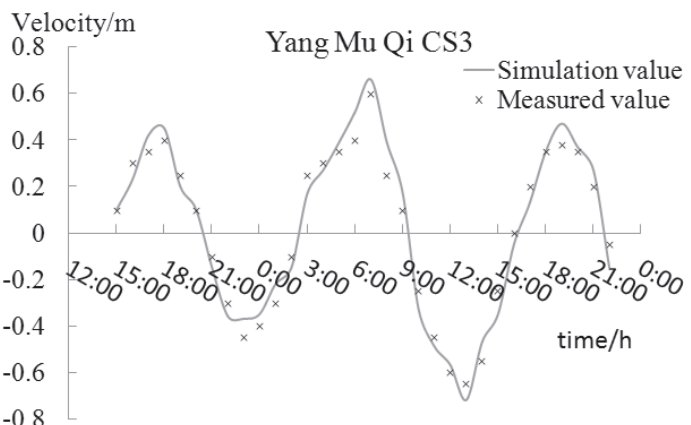

d)

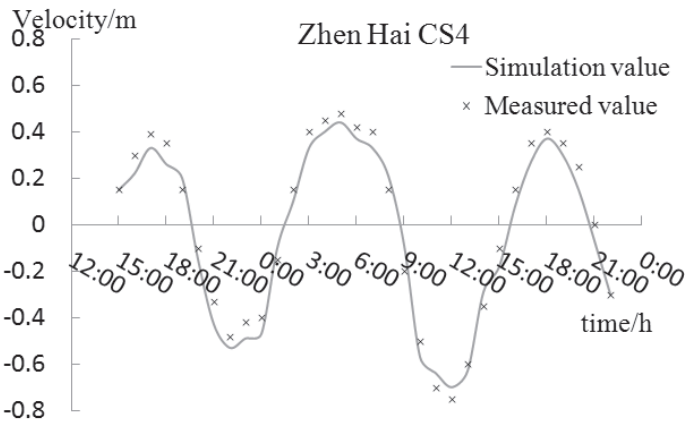

Fig. 4. Measured and simulated values of average flow velocity time series on each fracture surface: a) Average flow velocity of the CS6 Chen Lang Weir fracture surface; a) Average flow velocity of the CS2 San Jiang Kou fracture surface; c) Average flow velocity of the CS3 Yang Mu Qi fracture surface, and d) Average flow velocity of the CS4 Zhen Hai fracture surface.

to increase accordingly (Fig. 5). When the discharge volume of the Fenghua River exceeded $60 \mathrm{~m}^{3} / \mathrm{s}$, the WUA increased rapidly along with the flow volume and was only $5800 \mathrm{~m}^{2}$ when the average annual discharge volume was $60 \mathrm{~m}^{3} / \mathrm{s}$. When the flow exceeded $160 \mathrm{~m}^{3} / \mathrm{s}$, the WUA increased by seven times that of the conditions in which the average annual incoming flow was $60 \mathrm{~m}^{3} / \mathrm{s}$. When the discharge volume of the Fenghua reached $160 \mathrm{~m}^{3} / \mathrm{s}$, the WUA reached a maximum of $39,850 \mathrm{~m}^{2}$, covering $90 \%$ of the total area of spawning grounds Therefore, we determined that the suitable ecological flow of the Fenghua during the spawning period was $160 \mathrm{~m}^{3} / \mathrm{s}$ in the WUA-flow relationship curve (Fig. 5). In addition, based on the WUA changing in relation to $60 \mathrm{~m}^{3} / \mathrm{s}$ and $120 \mathrm{~m}^{3} / \mathrm{s}$, we found that increasing the flow of Fenghua through scheduling effectively increased the habitat area of the spawning grounds to provide fish with the appropriate hydrodynamic spawning environment.

Table 2. Verification of maximum flow direction of each section.

\begin{tabular}{|c|c|c|c|c|c|c|}
\hline \multirow[t]{2}{*}{ Section } & \multicolumn{2}{|c|}{$\begin{array}{l}\text { The maximum flow rate at high tide } \\
\qquad(\mathrm{m} / \mathrm{s})\end{array}$} & \multirow{2}{*}{$\begin{array}{l}\text { Flow rate } \\
\text { difference }\end{array}$} & \multicolumn{2}{|c|}{$\begin{array}{l}\text { The maximum flow direction at high tide } \\
\qquad\left({ }^{\circ}\right)\end{array}$} & \multirow{2}{*}{$\begin{array}{l}\text { Flow direction } \\
\text { difference }\end{array}$} \\
\hline & Measured value & simulated values & & Measured value & simulated values & \\
\hline CS6 & 0,6 & 0,58 & 0,2 & 236 & 247 & 11 \\
\hline $\mathrm{CS} 2$ & 1,34 & 1,26 & 0,08 & 192 & 211 & 19 \\
\hline $\mathrm{CS} 3$ & 0,67 & 0,61 & 0,06 & 230 & 244 & -14 \\
\hline $\mathrm{CS} 4$ & 0,48 & 0,43 & 0,05 & 247 & 256 & -18 \\
\hline \multirow[t]{2}{*}{ Section } & \multicolumn{2}{|c|}{$\begin{array}{l}\text { The maximum flow rate at low tide } \\
\qquad(\mathrm{m} / \mathrm{s})\end{array}$} & \multirow{2}{*}{$\begin{array}{l}\text { Flow rate } \\
\text { difference }\end{array}$} & \multicolumn{2}{|c|}{$\begin{array}{l}\text { The maximum flow direction at low tide } \\
\qquad\left(^{\circ}\right)\end{array}$} & \multirow{2}{*}{$\begin{array}{c}\text { Flow directior } \\
\text { difference }\end{array}$} \\
\hline & Measured value & simulated values & & Measured value & simulated values & \\
\hline CS6 & $-0,61$ & $-0,59$ & 0,2 & 88 & 80 & 11 \\
\hline $\mathrm{CS} 2$ & $-0,87$ & $-1,02$ & 0,15 & 30 & 22 & 8 \\
\hline $\mathrm{CS} 3$ & $-0,72$ & $-0,65$ & $-0,07$ & 74 & 61 & 13 \\
\hline CS4 & $-0,77$ & $-0,71$ & $-0,06$ & 77 & 54 & 17 \\
\hline
\end{tabular}




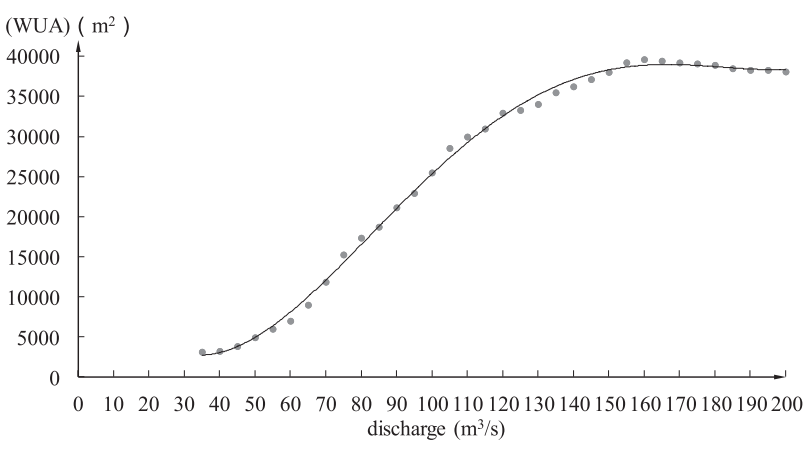

Fig. 5. WUA-flow relationship curve of viscous fish roes.

The effective habitat area distribution was determined by investigating the distribution of the twodimensional suitability indices at the spawning site (Fig. 6) when the average annual discharge volume reached $60 \mathrm{~m}^{3} / \mathrm{s}$ in the Fenghua. The local marginal beach on the right bank could reach the optimal level in the watershed (0.6-1.0) as marked by the yellow, orange, and red areas in the figure. Most of the area was under unsuitable conditions ( $0-0.1$, marked by purple) and very low suitability $(0.2-0.5$, areas are marked by blue and green). When the discharge volume of the Fenghua reached $160 \mathrm{~m}^{3} / \mathrm{s}$, which was the suitable ecological flow, the suitability of the spawning site significantly increased (Fig. 7). The effective habitat area basically reached the levels of moderate suitability or higher from Yinzhou Bridge to the Cheng Lang Weir (0.6-0.9). However, the unsuitable area still existed on the marginal beach of the left bank when the flow increased to $160 \mathrm{~m}^{3} / \mathrm{s}(0-0.2)$, which could be attributed to the degree of the marginal beach canalisation of city watercourse in the Yongjiang watershed. When the flow continued to increase and reached a maximum, the WUA likely decreased. The historical flow data over the years showed that the incoming flow of the Fenghua did not reach $200 \mathrm{~m}^{3} / \mathrm{s}$; therefore, we did not analyse the effective habitats relevant to the continuous growth in flow in detail.

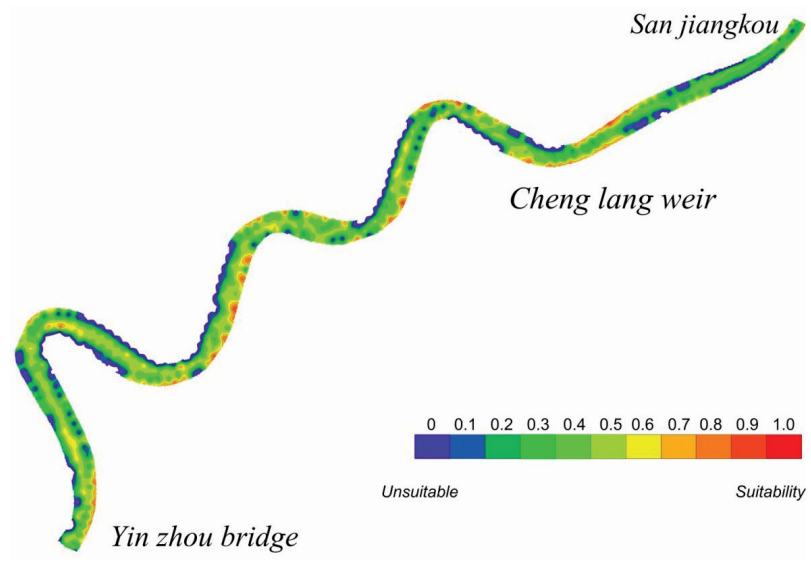

Fig. 6. Spawning site suitability index at the incoming flow of $60 \mathrm{~m}^{3} / \mathrm{s}$.

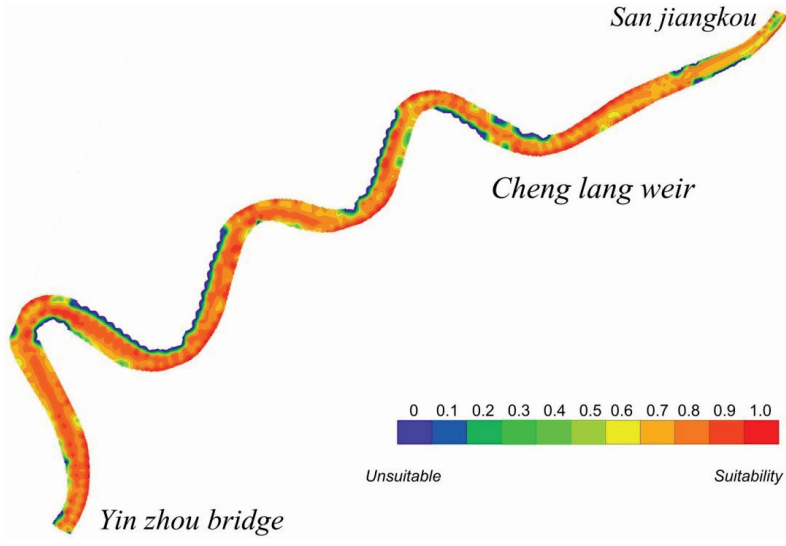

Fig. 7. Spawning site suitability index at the incoming flow of $160 \mathrm{~m}^{3} / \mathrm{s}$.

\section{Suitable Discharge Volume under the United Operation of Gate Dams in the Watershed}

After determining the suitable ecological flow $\left(160 \mathrm{~m}^{3} / \mathrm{s}\right)$ of target species in the Fenghua River spawning site, it was necessary to establish the size of discharge volume during the spawning period of yellowcheek carp in the Yaojiang and Yongjiang rivers to stimulate upstream migration to the Fenghua for spawning. The average discharge volumes of the Fenghua, Yaojiang, and Yongjiang rivers were considered as the benchmark hydrodynamic setting (Table 1, Scheme 0). In the remaining cases (Schemes 1-5), the flow of the Fenghua was fixed at $160 \mathrm{~m}^{3} / \mathrm{s}$ (the ecologically suitable flow), whereas the discharges of the Yaojiang River and Yongjiang gate were gradually increased to create adjustment schemes for the purpose of increasing flow velocity. The degree of change in the flow velocities of the watershed before and after the implementation of each scheme was determined by generating the contour maps representing the difference in flow velocities between each scheme (Schemes 1-5) and the benchmark scheme Figs (8 to 12).

The simultaneous operational plan of scheme 1 could meet the spawning migration stimulation signals in the spawning reach from Yinzhou Bridge to the San Jiang Kou Reach (Fig. 8). The Fenghua and Yaojiang rivers joined at San Jiang Kou, thus the watercourse was obviously broadened. The discharge area increased, but the flow velocity gradually decreased. A simulated increase in the flow velocity of about $0.15-0.20 \mathrm{~m} / \mathrm{s}$ was guaranteed in the local water area downstream of San Jiang Kou; however, that in the orange and red areas gradually decreased. Yet the increase in flow velocity was only $0.1-0.15 \mathrm{~m} / \mathrm{s}$ in the area of the Qing Shui Bridge, and some orange area still existed near the fracture surface mainly in the riverbed. In the downstream reach of San Jiang Kou, the area where the flow velocity reached $0.2 \mathrm{~m} / \mathrm{s}$ or more only accounted for $15 \%$ of the entire watershed; therefore, the Zhen Hai area was mainly covered in blue. The overall flow 
rate is concentrated in the range of $0.07 \sim 0.39 \mathrm{~m} / \mathrm{s}$ (Fig. 13). Thus, spawning stimulation could not be realized in the downstream region of San Jiang Kou after the implementation of Scheme 1.

The simultaneous operational scheme in Scheme 2 somewhat improved the added value of flow velocity in the downstream regions of San Jiang Kou, and the area where the added value of flow velocity reached $0.2 \mathrm{~m} / \mathrm{s}$ or above accounted for $45 \%$ of the entire watershed. It was mainly centred around the upstream area of San Jiang Kou (Fig. 9). The local orange area of the downstream San Jiang Kou suggested that the

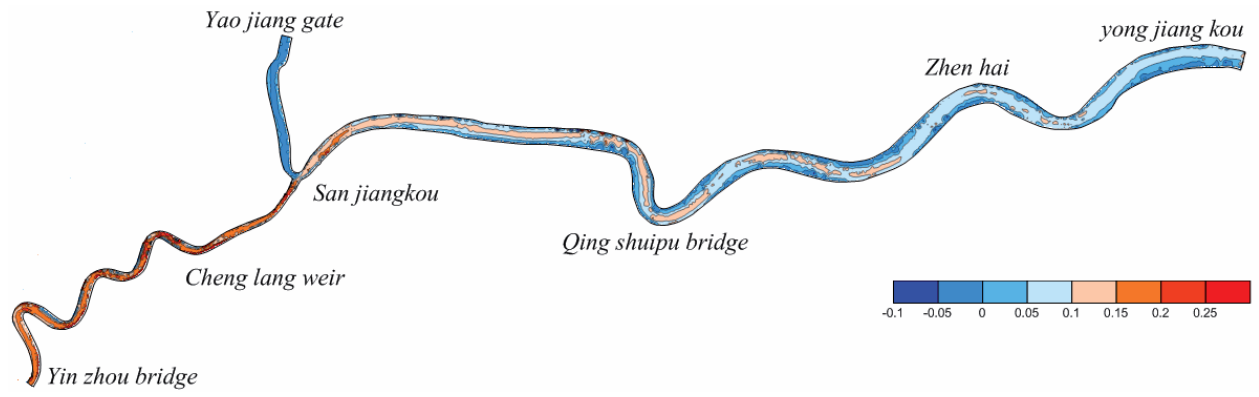

Fig. 8. Contour map of flow velocity differences of optimized pulse flow schemes 1 and 0 .

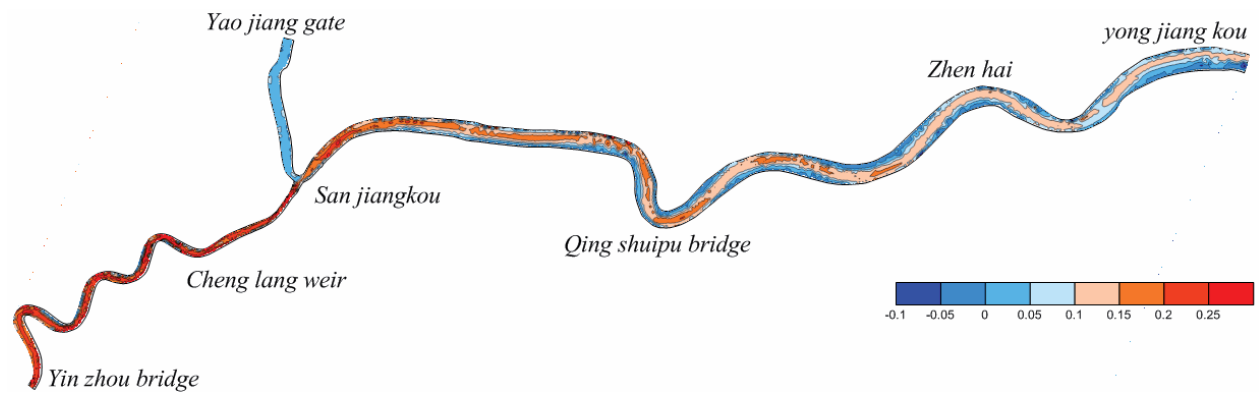

Fig. 9. Contour map of flow velocity differences of optimized pulse flow schemes 2 and 0.

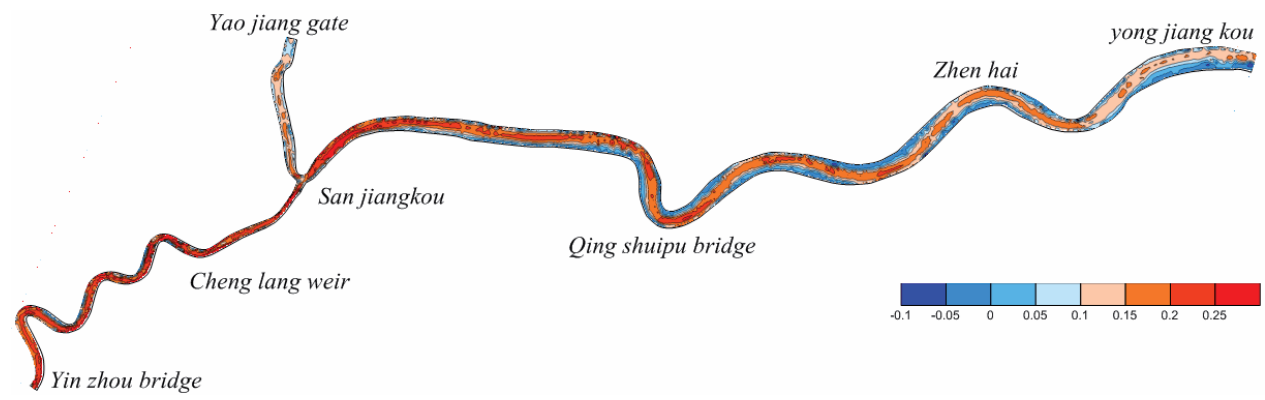

Fig. 10. Contour map of flow velocity differences of optimized pulse flow schemes 3 and 0.

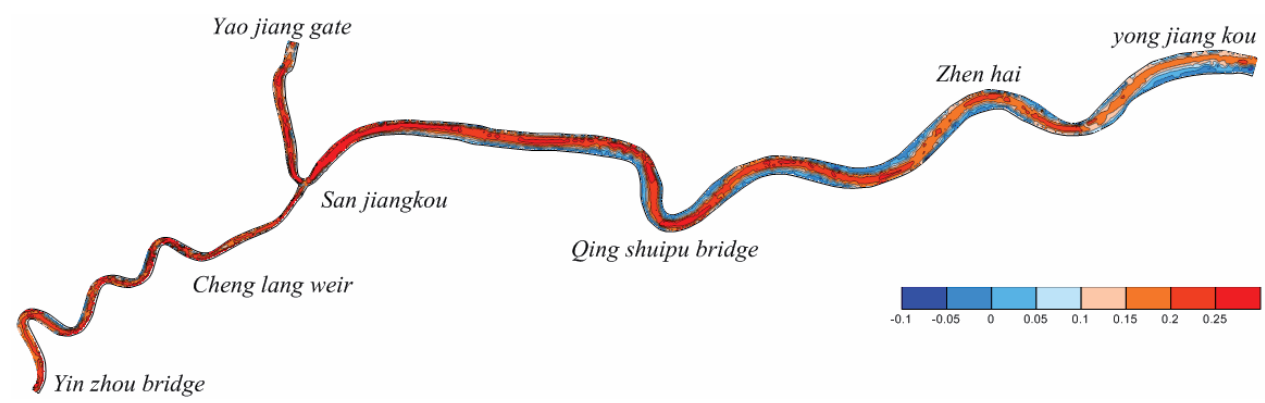

Fig. 11. Contour map of flow velocity differences of optimized pulse flow schemes 4 and 0. 


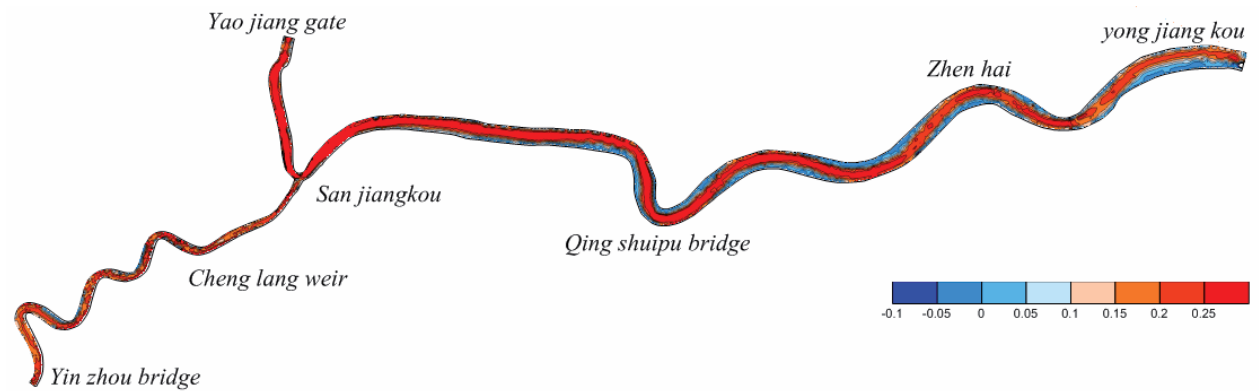

Fig. 12. Contour map of flow velocity differences of optimized pulse flow schemes 5 and 0.

added value of flow velocity by more than $0.20 \mathrm{~m} / \mathrm{s}$ was maintained, which then gradually decreased. The added value of flow velocity by $0.15-0.20 \mathrm{~m} / \mathrm{s}$ could be maintained near the Qingshui $\mathrm{Pu}$ Bridge, and the flow velocity of the local open section was maintained at $0.1-0.15 \mathrm{~m} / \mathrm{s}$. However, the range of the added value of flow velocity continued to decrease in the downstream reaches of the Qingshui $\mathrm{Pu}$ Bridge and was only $0.1-0.15 \mathrm{~m} / \mathrm{s}$ on the fracture surface of Yongjiang estuary. The overall flow rate is in the range of $0.09 \sim 0.48 \mathrm{~m} / \mathrm{s}$ (Fig. 13). This finding suggests that the added value of flow velocity was certainly improved by increasing the discharge volume at Yaojiang gate, but required further optimization.

The results of Scheme 3 are shown in Fig. 10. The area where the added value of flow velocity reached $0.2 \mathrm{~m} / \mathrm{s}$ or more accounted for $65 \%$ of the entire watershed, indicating that, unlike in Scheme 2 , the added value of flow velocity increased in the watercourse. Thus, the flow velocity amplification stimulation of $0.20-0.25 \mathrm{~m} / \mathrm{s}$ could be satisfied in most areas on the fracture surface of Qingshui $\mathrm{Pu}$ Bridge. However, the proportion of the orange area gradually degreased from Qingshui $\mathrm{Pu}$ Bridge to the Zhenhai Watershed. Yet the flow velocity amplification of $0.2 \mathrm{~m} / \mathrm{s}$ could not be satisfied in most areas from Zhenhai Station to the Yongjiang River estuary. The continuous water flow amplification stimulation could not be formed on the fracture surface downstream of Qingshui $\mathrm{Pu}$ Bridge, requiring further optimization.

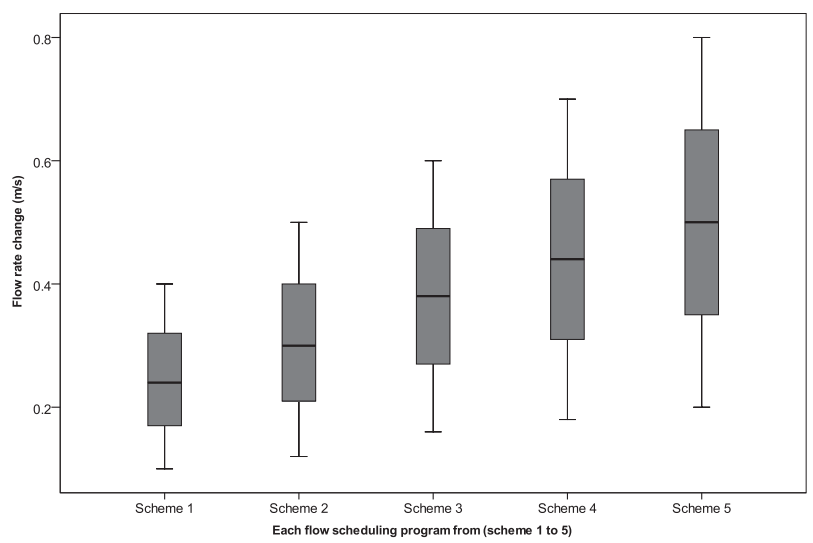

Fig. 13. Range of flow velocities in each flow scheduling.
In addition, with increasing flow in Yaojiang River, the average flow velocity of the mainstream section of Yongjiang River gradually increased. As shown in scheme 1 to scheme 3, the overall flow rate of case 3 is in the range of $0.17 \sim 0.60 \mathrm{~m} / \mathrm{s}$ (Fig. 13). However, the main flow rate range remained slightly lower than that suitable for yellowcheek carp.

Scheme 4 is shown in Fig. 11. The area where the added value of the flow velocity reached $0.2 \mathrm{~m} / \mathrm{s}$ or more accounted for $75 \%$ of the entire watershed, and the area between Yinzhou Bridge and Zhenhai section remained light red, indicating that the upstream migration pathway of the estuary could connect with the spawning site of the Fenghua River to form continuous water flow stimulation. This result was consistent with the flow velocity changes of spawning stimulation. At this point, as shown in Scheme 4 of Figure 13, the overall flow rate ranges from 0.20 to $0.68 \mathrm{~m} / \mathrm{s}$ in the mainstream section of Yongjiang, and was optimal in the area containing yellowcheek carp swimming upstream.

Scheme 5 is shown in Fig. 12. The area where the added value of the flow velocity reached $0.2 \mathrm{~m} / \mathrm{s}$ or more accounted for $85 \%$ of the entire watershed, and only a partial area was orange between Zhenhai and Yongjiang estuaries, indicating that the flow velocity stimulation objective was achieved in Scheme 5. As shown in Scheme 5 of Fig. 13, the flow velocity stimulation amplification was further increased, but the flow velocity ranged from 0.25 to $0.85 \mathrm{~m} / \mathrm{s}$ in the watershed. The average flow velocity exceeded the optimal flow velocity range for yellowcheek carp swimming upstream on the partial fracture surface, especially from San Jiang Kou to Qingshui Pu Bridge, where the overall flow velocity of the main river channel is in the range of $0.21 \sim 0.79 \mathrm{~m} / \mathrm{s}$, and already exceeded $0.6 \mathrm{~m} / \mathrm{s}$. It had a negative influence on the smooth upstream swimming of fish.

In conclusion, Scheme 4 was found to be the optimal operational scheme for the minimum flow velocity amplification stimulation that meets the requirements for fish spawning migration. The fish in the Yongjiang stream were stimulated to migrate to the Fenghua River spawning site for spawning by maintaining a suitable ecological flow of $160 \mathrm{~m}^{3} / \mathrm{s}$ in the Fenghua. In addition, a flow volume of 90 and $250 \mathrm{~m}^{3} / \mathrm{s}$ should be discharged from the Yaojiang and Yongjiang gates, respectively. 
Suggestions Regarding the Ecological Flow

Regulation of Gates during the Fish Spawning Period

At present, an increasing number of studies has focused on the relationship between water flow regime and fish reproduction. These studies have shown that the flow process is optimised after hydraulic engineering construction during the fish spawning period. Li [42] analysed the requirements of flow velocity and water depth for fish spawning in the Chinese Lijiang River in different periods by using a self-developed habitat model and used the habitat model to calculate the effective habitat area, effective habitat quality, and habitat fragmentation index, which reflect the suitability of discharge flow in the Qing Shi Tan reservoir. This information was also used to provide suggestions on how to regulate reservoir flow. Yi [43] analysed the required flow scope in the water environment for fish spawning in the Yangtze River by using the YFMCS habitat suitability model in the middle reaches of the Yangtze, and proposed the flow operational suggestions under different flows based on the current discharge status of the dam. However, most studies only focused on the hydrodynamic requirements during fish spawning without providing reasonable regulation strategies for the hydrodynamic conditions of target fish species during fish spawning migration.

To our knowledge, the habitat model was first used in this study in order to reflect on the suitability of water depth and flow velocity at fish spawning sites by considering the size of the effective habitat area. The suitable ecological flow of the spawning site was determined to guarantee that the flow velocity change rate of the Fenghua River spawning site could meet the minimum change in the rate of the flow velocity to stimulate fish spawning. Based on the flow velocity of fish spawning stimulation, this study further investigated the change in flow velocity requirements for stimulating fish migration, which is an important factor that has been rarely investigated by previous studies. Therefore, unlike the regulation scheme of the single habitat method, the optimal gate regulation scheme finally selected in this study could better meet the water flow requirements during the entire process of fish spawning migration, and had stronger ecological significance.

The volume of spawning is a crucial factor influencing the quantity of the fish population; therefore, it is an important factor in the process of fish reproduction [44]. Fish spawning is mainly influenced by certain factors, including flow velocity stimulation, water flow temperature, duration, dispatching cycle, and human activities. This study proposed the ecological flow regulation scheme according to the protection of yellowcheek carp spawning. A series of actual external conditions in the regulation period should be considered in the scheme, including water flow temperature, duration, dispatching cycle, and human activities. According to historical data analysis, yellowcheek carp might not spawn when the water temperature is lower than $18^{\circ}$. The reproduction of yellowcheek carp starts as early as mid-April in the Yongjiang River, but the spawning time varies every year due to global climate change and the influence of low-temperature water discharged upstream of the Fenghua River reservoir. The water temperature meets the spawning requirement in mid-May; hence, the optimized ecological gate flow should be used for regulation according to changes in water temperature between mid-April and mid-May. After mid-May, the water temperature completely meets the suitable spawning temperature requirement, and the regulation of ecological gate flow should be conducted to a maximum. Given the reflection time of water flow stimulation in roe incubation and the time from roe incubation to embryonic development [43], ecological gate flow regulation should last for five to seven days. In terms of spawning regulation frequency, human activities should be given careful consideration. In June or July, discharge flow before the flood season and flood discharge of rainfall should be combined to use natural incoming flow effectively to promote the increase of flow velocity. It is necessary to conduct a 5-7-day ecological dam flow scheduling. When the stimulation of the roe incubation and hydrodynamic spawning environment is maintained in the Yongjiang watershed, the water resources should be rationally utilized to completely fit the hydrological and ecological rules during the fish spawning period.

Other factors that might affect actual flow management processes during the spawning migration of fish species were not considered in this study, including agricultural irrigation, water for everyday activities, and other factors that require the sharing of water units. However, the regulation of ecological water requirements would restrict water use for human activities in actual processes, and cause some losses to the social economic benefits [45-47]. Because the quantity of ecological water used for consumption is important, the administrators of water resources need to ensure that ecological water requirements, production, and life are balanced. Therefore, the water use benefits need to be further optimized for multipurpose regulation processes. In addition, this study focuses on refining the criteria for the biological water demand process, ignoring the uncontrollable impact of different climate change models on flow scheduling. As the climate changes, the hydrological process will change, and at the same time, human consumption will also undergo important changes. Therefore, in the basin's ecological flow, especially for the ecological flow of fish protection, it is necessary to maintain a dynamic balance so as to achieve acceptable ecological points for human demand and aquatic life. And forecasting the dynamic balance point of ecological flow under future climate change will be the future research trend. In future studies, we plan to study the impact of different climate models on fish water allocation. 


\section{Conclusions}

This study focused on the hydrodynamic requirements for the spawning migration of fish during reproduction. The flow regulation scheme for facilitating yellowcheek carp spawning migration in the Yongjiang River was established by determining suitable flow at the spawning site and analyzing the water quantity regulation of dam gates in the watershed. First, the MIKE hydrodynamic model was combined with PHABSIM to simulate the habitat and determine the suitable incoming flow in the Fenghua River spawning site for yellowcheek carp, which was found to be $160 \mathrm{~m}^{3} / \mathrm{s}$. Considering the incubated water flow environment, the flow velocity stimulation requirements during fish spawning migration were determined as the flow velocity amplification of $0.2 \mathrm{~m} / \mathrm{s}$. Preliminary investigations revealed that the discharge flows of the Yaojiang and Yongjiang stream gates need to be increased to 90 and $250 \mathrm{~m}^{3} / \mathrm{s}$, respectively. The calculations were performed for both water bodies together, as well as individually, to ensure a 5-7-day flow regulation cycle for fish spawning and to fulfil the hydrodynamic requirements during the spawning period of yellowcheek carp. In conclusion, this study developed an effective regulation strategy to determine the water flow process requirements during fish spawning migration and enhance the protection of fish habitats.

\section{Acknowledgments}

This study received financial support from the National Basic Research Program of China (973 Program, 2015CB452701), the National Natural Science Foundation of China (51509265 and 51625904), and the National Key Research Program of China (2016YFC0401302).

\section{Conflict of Interest}

This manuscript has not been published or presented elsewhere in part or whole, and is not under consideration by another journal.

\section{References}

1. MORAIS P., MARTINS F., CHICHARO M.A., LOPES J., CHICHARO L. Merging anchovy eggs abundance into a hydrodynamic model as an assessment tool for estuarine ecohydrological management. River Research and Applications, 28 (2), 160, 2012.

2. TIEMANN J.S., GILLETTE D.P., WILDHABER M.L., EDDS D.R. Effects of lowhead dams on riffle-dwelling fishes and macroinvertebrates in a midwestern river. Transactions of the American Fisheries Society, 133 (3), 705, 2004.
3. MAO Z.P., WANG Y.C., PENG W.Q., ZHOU H.D. Advances in effects of dams on river ecosystem. Advances in Water Science. 16 (1), 134, 2005.

4. MAGILLIGAN F.J., NISLOW K.H. Changes in hydrologic regime by dams. Geomorphology, 71 (1), 61, 2005.

5. GRILL G., DALLAIRE C.O., CHOUINARD E.F., SINDORF N., LEHNER B. Development of new indicators to evaluate river fragmentation and flow regulation at large scales: a case study for the Mekong River Basin. Ecological Indicators, 45 (5), 148, 2014.

6. BURKE M., JORDE K., BUFFINGTON J.M. Application of a hierarchical framework for assessing environmental impacts of dam operation: changes in streamflow, bed mobility and recruitment of riparian trees in a western North American river. Journal of Environmental Management, 90, 224, 2009.

7. KINGSFORD R.T., CURTIN A.L., PORTER J. Water flows on Cooper Creek in arid Australia determine 'boom'and 'bust'periods for waterbirds. Biological Conservation, 88 (2), 231, 1999.

8. BUNN S.E., THOMS M.C., HAMILTON S.K., CAPON S.J. Flow variability in dryland rivers: boom, bust and the bits in between. River Research and Applications, 22 (2), 179, 2006.

9. RAYNER T.S., KINGSFORD R.T., SUTHERS I.M., CRUZ D.O. Regulated recruitment: native and alien fish responses to widespread floodplain inundation in the Macquarie Marshes, arid Australia. Ecohydrology, 8 (1), 148, 2015.

10. MCDONNELL R.A. Hierarchical modelling of the environmental impacts of river impoundment based on a GIS. Hydrological Processes, 14 (11), 2123, 2015.

11. LAMOUROUX N., POFF L.R., ANGERMEIER P.L. Intercontinental Convergence of Stream Fish Community Traits along Geomorphic and Hydraulic Gradients. Ecology, 83 (7), 1792, 2002.

12. WEERD J.H., SUKKEL M., KECHIK, I.B.A., BONGERS A.B.J., RICHTER C.J.J. Pheromonal stimulation of ovarian recrudescence in hatchery-raised adult African catfish, Clariasgariepinus. Aquaculture, 90 (3), 369, 1990.

13. RICHTER B.D., BAUMGARTNER J.V., BRAUU D.P., POWELL J. A spatial assessment of hydrologic alteration within a river network. River Research and Applications, 14 (4), 329, 1998.

14. SOUCHON Y., CAPRA H. Aquatic habitat modelling: biological validations of IFIM/PHABSIM methodology and new perspectives. Hydroécologie Appliquée, 14 (1), $9,2007$.

15. LAMOUROUX N., CAPRA H. Simple predictions of instream habitat model outputs for target fish populations. Freshwater Biology. 47 (8), 1543, 2002.

16. GORSKI K., WINTER H.V., DE L.J., MININ A., NAGELKERKE L. Fishspawning in a large temperate floodplain: the role of flooding and temperature.Freshwater Biology. 55 (7), 1509, 2010.

17. YAO W., LIU H., CHEN Y., ZHANG W., ZHONG Y., FAN H. Simulating Spawning and Juvenile Rainbow Trout (Oncorhynchus mykiss) Habitat in Colorado River Based on High-Flow Effects. Water, 9 (3), 150, 2017.

18. CHEN Q., CHEN D., HAN R., LI R., MA J., BLANCKAERT $K$. Optimizing the operation of theQingshitan reservoir in the Lijiang River for multiple human interests and quasinatural flow maintenance. Journal of Environmental Sciences, 24 (11), 1923,2012. 
19. LI T., CAI S., YANG H.D., WANG X.L., WU S.J., REN X.Y. Fuzzy comprehensive quantifying assessment in analysis of water quality: a case study in Lake Honghu, China. Environ. Eng. Sci. 26 (2), 451, 2009.

20. THARME R.E. A global perspective on environmental flow assessment: emerging trends in the development and application of environmental flow methodologies for rivers. River research and applications, 19 (5), 397, 2003.

21. RUIZHI C., YANG S., WANG Z., ZONG L.I. Variability of precipitation in the Yongjiang River Basin during 1956-2010. Progress in Geography, 31 (9), 1149,2012.

22. ZHU F J., MA J., TU C.J. Reflections on the networked layout of coastal plains in Zhejiang Province. Water Conservancy Development Research, 16 (6),36,2016.

23. YAFEI G.E. The current situation and conservation measures of the rare aquatic animal resources in Zhejing Province. Journal of Zhejiang Ocean University (Natural Science), 1, 2006.

24. CHU N.S., CHEN H.S. On the food and feeding habits of elopichthys bambusa in liangtze lake. Acta Hydrobiological Sinica, 3, 262, 1959.

25. LIU E.S. Analysis on bio-manipulation, non-traditional bio-manipulation and discussion of the countermeasures of bio-manipulation application in water.Journal of Lake Sciences, 22, 307, 2010.

26. LI Y.F., LI X.H., YANG J., JIE L.I., SHUAI F. Status of Elopichthys bambusa recruitment stock after the impoundment of Changzhou Hydro-junction in Pearl River. 27 (5), 917, 2015.

27. KITAMURA W., KOBAYASHI M. The effect of water flow on spawning in the medaka, Oryziaslatipes. Fish Physiology and Biochemistry, 28 (1), 429, 2004.

28. ZHOU C., LIANG Z. Ecological features of the spawning of certain fishes in the hanjiang river after the construction of dams. Acta Hydrobiologica Sinica, 175, 1980.

29. KING A.J., TONKIN Z., MAHONEY J. Environmental flow enhances native fish spawning and recruitment in the Murray River, Australia. River Research and Applications, 25(10), 1205, 2009.

30. COLIN P.L. Aggregation and spawning of the humphead wrasse Cheilinusundulatus (Pisces: Labridae): general aspects of spawning behaviour. Journal of Fish Biology, $\mathbf{7 6}$ (4), 987, 2010.

31. LIANG Z., YI B., YU Z., WANG N. Spawning areas and early development of long spiky-head carp (Luciobrama macrocephalus) in the Yangtze River and Pearl River, China. Hydrobiologia, 490 (1), 169, 2003.

32. TANG M.Y., HUANG D. Grass, green, silver carp, egg test hydraulic characteristics of bighead and its incubation conditions in the Three Gorges Reservoir Area. preliminary forecast water fisheries, 26, 1989.

33. GEORGE A.E., GARCIA T., CHAPMAN D.C. Comparison of Size, Terminal Fall Velocity, and Density of Bighead Carp, Silver Carp, and Grass Carp Eggs for Use in Drift Modeling. Transactions of the American Fisheries Society, 146 (5), 834,2017.

34. GORE J.A., CRAWFORD D.J., ADDISON D.S. An analysis of artificial riffles and enhancement of benthic community diversity by physical habitat simulation
(PHABSIM) and direct observation. River Research and Applications, 14 (1), 69, 2015.

35. AHNADIN.B., HILAIRE A., BÉRUBÉ M., ÉLAINE R., THIÉMONGE N., BOBÉE B. A review of statistical methods for the evaluation of aquatic habitat suitability for instream flow assessment. River Research and Applications, 22 (5), 503,2006.

36. GORE J.A., NESTLER J.M. Instream flow studies in perspective. River Research and Applications, 2 (2), 93, 1988.

37. WU R.S., MAO C.T. The assessment of river ecology and habitat using a two-dimensional hydrodynamic and habitat model. Journal of Marine Science and Technology, 15 (4), $322,2007$.

38. CAPER A.F., DIXON B., EARLS J., GORE J.A. Linking a spatially explicit watershed model (SWAT) with an in - stream fish habitat model (PHABSIM): A case study of setting minimum flows and levels in a low gradient, sub - tropical river. River Research \& Applications, 27 (3), 269, 2015.

39. LOAR J.M., SALE M.J. Analysis of environmental issues related to small-scale hydroelectric development. V. Instream flow needs for fishery resources. Reports, 1981.

40. PAN B.Z., WANG H.Z., BAN X., YIN X.A. An exploratory analysis of ecological water requirements of macro-invertebrates in the Wuhan branch of the Yangtze River. Quaternary International, 380, 2015.

41. REMYA P.G., KUMAR R., BAUU S., SARKAR A. Wave hind cast experiments in the Indian Ocean using MIKE 21 SW model. Journal of Earth System Science, 121 (2), 385, 2012.

42. LI W., CHEN Q., CAI D., LI R. Determination of an appropriate ecological hydrograph for a rare fish species using an improved fish habitat suitability model introducing landscape ecology index. Ecological Modelling, 311, 31, 2015.

43. YI Y.J., WANG Z.Y., YANG Z.F. Impact of the Gezhouba and Three Gorges Damson habitat suitability of carps in the Yangtze River. Journal of Hydrology, 387 (3), 283, 2010.

44. COCKAYNE B.J., McDougall A.J. Riverine flow and spawning requirements of Macquaria ambiguaoriens: implications for conservation and management. Marine and Freshwater Research, 64 (1), 42-53, 2013.

45. CHEN Q., CHEN D., LI R., MA J., BLANCKAERT K. Adapting the operation of two cascaded reservoirs for ecological flow requirement of a de-watered river channel due to diversion-type hydropower stations. Ecological Modelling, 252 (1), 266, 2013.

46. ZHAO Y., YING H., ZHOU J. Multi-objective optimization of the Three Gorges cascaded reservoirs operation with emphasis on electricity generation and ecological requirements. Water Science and Technology: Water Supply, 15 (4), 753, 2015.

47. WEN X., FANG G.H., GUO Y.X., ZHOU L. Adapting the operation of cascaded reservoirs on Yuan River for fish habitat conservation. Ecological Modelling, 337, 221, 2016. 